\title{
Age Hardening in Ultrafine-Grained Al-2 Pct Fe Alloy Processed by High-Pressure Torsion
}

\begin{abstract}
JORGE M. CUBERO-SESIN and ZENJI HORITA
A cast Al-2 wt pct Fe alloy was processed by high-pressure torsion (HPT) at room temperature and then subjected to artificial aging at temperatures of $373 \mathrm{~K}$ and $473 \mathrm{~K}\left(100{ }^{\circ} \mathrm{C}\right.$ and $\left.200{ }^{\circ} \mathrm{C}\right)$. The aging behavior was studied by Vickers microhardness measurements and by microstructural analyses using transmission electron microscopy and X-ray diffraction. The initial intermetallic structures, composed of a mixture of $\mathrm{Al}+\mathrm{Al}_{6} \mathrm{Fe}$ and $\mathrm{Al}+\mathrm{Al}_{3} \mathrm{Fe}$ eutectics phases, were partially dissolved in the matrix up to a supersaturation of $\sim 1$ wt pet Fe. The microstructure was refined by HPT to an ultrafine-grained level with a minimum grain size of $\sim 120 \mathrm{~nm}$ in the matrix and a dispersion of particles less than $400 \mathrm{~nm}$. Age hardening was achieved within 0.25 hours at $473 \mathrm{~K}\left(200{ }^{\circ} \mathrm{C}\right)$, to a maximum UTS of $\sim 700 \mathrm{MPa}$ as a result of nano-sized precipitation within the ultrafine grains. The uniform elongation exceeded $\sim 12$ pct even at intermediate levels of imposed strain by HPT, while it decreased to $\sim 6$ pct with the subsequent aging treatment. The thermal stability of the ultrafine-grained structure was verified to exceed 16 days at $373 \mathrm{~K}\left(100{ }^{\circ} \mathrm{C}\right)$ and 12 hours at $473 \mathrm{~K}\left(200^{\circ} \mathrm{C}\right)$.
\end{abstract}

DOI: $10.1007 / \mathrm{s} 11661-015-2876-6$

(C) The Minerals, Metals \& Materials Society and ASM International 2015

\section{INTRODUCTION}

THE fabrication capability of bulk ultrafine-grained (UFG) and nanocrystalline (NC) metallic materials has been well established by the different techniques of severe plastic deformation (SPD), particularly by highpressure torsion (HPT).$^{[1-3]}$ The application of HPT to metallic alloys is now an active area of research due to the superior grain refinement. ${ }^{[3,4]} \mathrm{Al}$ alloys are not an exception to this advantage and much research has been carried out in different alloy systems using HPT processing. ${ }^{[5]}$ In this sense, a synergistic combination of the grain refinement with additional strengthening mechanisms such as dispersion or precipitation of the secondary phases becomes an important factor.

$\mathrm{Fe}$ is the main impurity in $\mathrm{Al}$ and has potential as an inexpensive alloying element for strengthening. However, due to its low solubility in $\mathrm{Al}, \mathrm{Fe}$ may be present as secondary phases in the form of intermetallics. ${ }^{[6-12]}$ Although it has been demonstrated that these particles can strengthen and increase the temperature resistance with little increase in weight, an effective use of $\mathrm{Fe}$ as a major alloying element in structural alloys of $\mathrm{Al}$ has not

JORGE M. CUBERO-SESIN, formerly with the Department of Materials Science and Engineering, Faculty of Engineering, Kyushu University, Fukuoka, 819-0395 Japan, and also with the WPI, International Institute for Carbon-Neutral Energy Research (WPII2CNER), Kyushu University, is now Lecturer and Researcher with the Escuela de Ciencia e Ingeniería de los Materiales, Instituto Tecnológico de Costa Rica, Cartago 159-7050, Costa Rica. Contact e-mail: jcubero@itcr.ac.cr ZENJI HORITA, Professor, is with the Department of Materials Science and Engineering, Faculty of Engineering, Kyushu University, and also with the WPI, International Institute for Carbon-Neutral Energy Research (WPI-I2CNER), Kyushu University.

Manuscript submitted January 26, 2014.

Article published online April 7, 2015 been possible to date. The secondary phases cannot be manipulated easily through conventional deformation and heat treatment including supersaturation and subsequent aging for fine precipitation. ${ }^{[13]}$

The formation of fine eutectic structures in an Al-rich side of the Al-Fe system by manipulation of the solidification rate re,14-16] $^{[10 t i v a t e d ~ r e s e a r c h e r s ~ t o ~ e x-~}$ plore several methods to achieve microstructure control in this system, initially by deformation of the directionally solidified eutectic alloys. ${ }^{[17-19]}$ The earliest work which effectively achieved an extension of $\mathrm{Fe}$ solid solubility (namely supersaturation of $\mathrm{Fe}$ ) in $\mathrm{Al}$ involved rapid quenching (RQ). The work of Tonejc and Bonefacic $^{[20,21]}$ Jones ${ }^{[22,23]}$ and others ${ }^{[15,16,24-28]}$ demonstrated an increase in the Fe solubility to a maximum of 4.5 at. pct and the formation of several metastable second phases. However, extremely high cooling rates are required to achieve such high supersaturation. A similar level of $\mathrm{Fe}$ supersaturation and fine dispersion of second phases was achieved using mechanical alloying (MA) of elemental powder mixtures, ${ }^{[29-34]}$ but extended milling times and additional consolidation steps are required to form fully dense bulk samples.

The application of another out-of-equilibrium method such as HPT can introduce a high amount of strain and achieve microstructure control through grain refinement and dispersion of intermetallic phases. This method has clear advantages, when compared to RQ and MA, such that it can be applied to existing bulk samples with only a limited change to their shape. ${ }^{[2]}$ Additionally, the high supersaturation of Fe in the matrix that can be achieved by solid-state processing is most important to this study. In recent years, the capability of producing bulk Al-Fe alloys with supersaturation of $\mathrm{Fe}$ by HPT processing has been reported in a cast Al-11 pet Fe alloy ${ }^{[35]}$ and $\mathrm{Al}-2,8$ and 
10 pct Fe alloys initially processed by RQ and MA. ${ }^{[36]}$ Significant increases in microhardness (by $\sim 50 \mathrm{HV}$ in 2 pct $\mathrm{Fe}$ and by $>100 \mathrm{HV}$ in 8 to 11 pct $\mathrm{Fe}$ ) were shown by aging at temperatures ranging from $373 \mathrm{~K}$ to $473 \mathrm{~K}$ $\left(100{ }^{\circ} \mathrm{C}\right.$ to $\left.200{ }^{\circ} \mathrm{C}\right)$. However, no systematic study of the aging behavior of the HPT-processed Al-Fe alloys has been carried out to date. We recently reported ${ }^{[37]}$ a supersaturation of $\mathrm{Fe}$ in $\mathrm{Al}$ by $\sim 1$ pct $\mathrm{Fe}$ in $\mathrm{Al}-2$ pct $\mathrm{Fe}$ and Al-4 pct Fe alloys after application of HPT. The eutectic phases in these alloys were shown to be ideal for subsequent dispersion and dissolution of Fe by the HPT process. The potential for precipitation hardening by artificial aging was evaluated in this work. The structural changes that occur in the HPT-processed samples with aging are discussed in terms of the mechanical properties and microstructural analyses.

\section{EXPERIMENTAL PROCEDURES}

The starting material was a cast ingot with an $\mathrm{Fe}$ content of $1.99 \mathrm{wt}$ pct as used in a previous study. ${ }^{[37]}$ Disks with $10-\mathrm{mm}$ diameter and $0.9 \pm 0.1-\mathrm{mm}$ thicknesses were extracted from the ingot and placed between two anvils of the HPT facility at room temperature. Torsion was applied by rotating the lower anvil with respect to the upper anvil at $1 \mathrm{rpm}$ under a compressive load of $6 \mathrm{GPa}$. The thickness of the disks after HPT processing is $0.7 \pm 0.1 \mathrm{~mm}$. The shear strain introduced by HPT processing is a function of the number of revolutions $N$, the distance from the disk center $r$, and the thickness during HPT processing $t$. The following relation was used in this work to calculate the equivalent strain: ${ }^{[2]}$

$$
\varepsilon=\frac{2 \pi N r}{\sqrt{3} t}
$$

Post-HPT aging was performed at $373 \mathrm{~K}$ and $473 \mathrm{~K}$ $\left(100{ }^{\circ} \mathrm{C}\right.$ and $\left.200{ }^{\circ} \mathrm{C}\right)$ in air in an electric furnace with the temperature controlled to $\pm 0.5 \mathrm{~K}\left({ }^{\circ} \mathrm{C}\right)$. The aging at $373 \mathrm{~K}\left(100{ }^{\circ} \mathrm{C}\right)$ was carried out in boiling water for up to a total of 12 hours with the temperature controlled within a few degrees below $373 \mathrm{~K}\left(100{ }^{\circ} \mathrm{C}\right)$. The aging at each temperature was conducted using a single sample and was interrupted at different time intervals by quenching in ice water. Shortly after quenching and polishing the surface using an alumina powder solution, Vickers microhardness was measured by applying a load of $100 \mathrm{~g}$ for $15 \mathrm{~s}$ along radial directions of the disks. The tensile properties were also measured at room temperature using miniature tensile specimens extracted from the HPT-processed disks. The dimensions of the gage are $1.5 \mathrm{~mm}$ length, $0.7-\mathrm{mm}$ width, and $0.6-\mathrm{mm}$ thickness. The gage section is located at $2 \mathrm{~mm}$ from the disk center. The initial strain rate used in the test was $2 \times 10^{-3} \mathrm{~s}^{-1}$.

Disks with 3-mm diameter were punched from the periphery of the HPT-processed disks and analyzed by $\mathrm{X}$-ray diffraction (XRD) to estimate the Fe dissolution in the matrix by measuring change in the lattice constant of Al. The XRD was performed using the $\mathrm{Cu} \mathrm{K \alpha}$ radiation with a scanning speed of $0.5 \mathrm{deg} / \mathrm{min}$ and a step of $0.01 \mathrm{deg}$. $\mathrm{LaB}_{6}$ powder was used to correct for

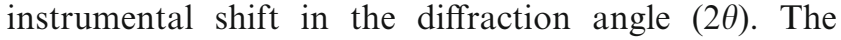
$3 \mathrm{~mm}$ disks were further thinned by electropolishing with a potential of $15 \mathrm{~V}$ in a solution of 20 pet sulfuric acid in methanol at $(278 \mathrm{~K}) 5{ }^{\circ} \mathrm{C}$ for transmission electron microscopy (TEM) at $200 \mathrm{kV}$. The average grain sizes were estimated either from the measurement of individual grains in dark-field images or by the linearintercept method using bright-field images.

\section{RESULTS AND DISCUSSION}

\section{A. Optical Microscopy}

Figure 1(a) shows an optical micrograph of the ascast microstructure. It is shown by the etching response that the casting contains a high fraction of eutectic phases surrounding the dendritic $\alpha$-Al phase. Close observation, as shown in Figure 1(b) for the region in the rectangle of Figure 1(a), shows two distinct eutectic phases as in the regions labeled $\mathrm{A}$ and $\mathrm{B}$. The presence of phase A which consists of $\mathrm{Al}$ and orthorhombic $\mathrm{Al}_{6} \mathrm{Fe}^{[8]}$ confirms that the cooling rate was sufficiently high to promote the formation of the metastable eutectic. ${ }^{[10,13]}$ Note that phase B corresponds to the equilibrium eutectic ${ }^{[13,14]}$ composed of $\mathrm{Al}$ and monoclinic $\mathrm{Al}_{3} \mathrm{Fe}^{[6,7]}$

It was shown ${ }^{[37]}$ that phase A contains fine fibers with diameters in the range of 150 to $200 \mathrm{~nm}$ and grouped in cellular structures of similar directions. The morphology of phase B consists of discontinued networks of lamellae forming platelets and ellipsoidal particles with widths below $\sim 1.5 \mu \mathrm{m}$. The combined volume fraction of both eutectic structures can be estimated in the range of 3.5 to 6 pct depending on the ratio of $\mathrm{Al}_{3} \mathrm{Fe} / \mathrm{Al}_{6} \mathrm{Fe}$ in the casting and depending on the position from the edge of the ingot. ${ }^{[10]}$

Figure 1(c) shows a microstructure of the sample after HPT processing for $N=75$ revolutions. Grain refinement in the $\alpha$-Al phase is achieved beyond the resolution of optical microscopy and a homogeneous dispersion of the eutectic particles is observed. Due to the etching response of $\mathrm{Al}_{3} \mathrm{Fe}$ when compared to $\mathrm{Al}_{6} \mathrm{Fe}$, the phase $\mathrm{B}$ appears in a darker contrast. ${ }^{[13]}$ Thus, the largest particles in Figure 1(c) are associated with the fragmented $\mathrm{Al}_{3} \mathrm{Fe}$ platelets. The average size of these particles is determined to be $\sim 400 \mathrm{~nm}$ using image processing. The contrast from phase A is not clearly distinguishable in Figure 1(c) which is a result of the particle dispersion and refinement, but also suggests that partial dissolution occurred in the matrix.

\section{B. Microhardness Evolution with Imposed Strain and Isothermal Aging}

Figure 2 shows the evolution of Vickers microhardness with respect to the equivalent strain imposed by HPT processing and after four different periods of isothermal aging at $473 \mathrm{~K}\left(200{ }^{\circ} \mathrm{C}\right)$. The trend in microhardness is delineated by a solid line for the as- 

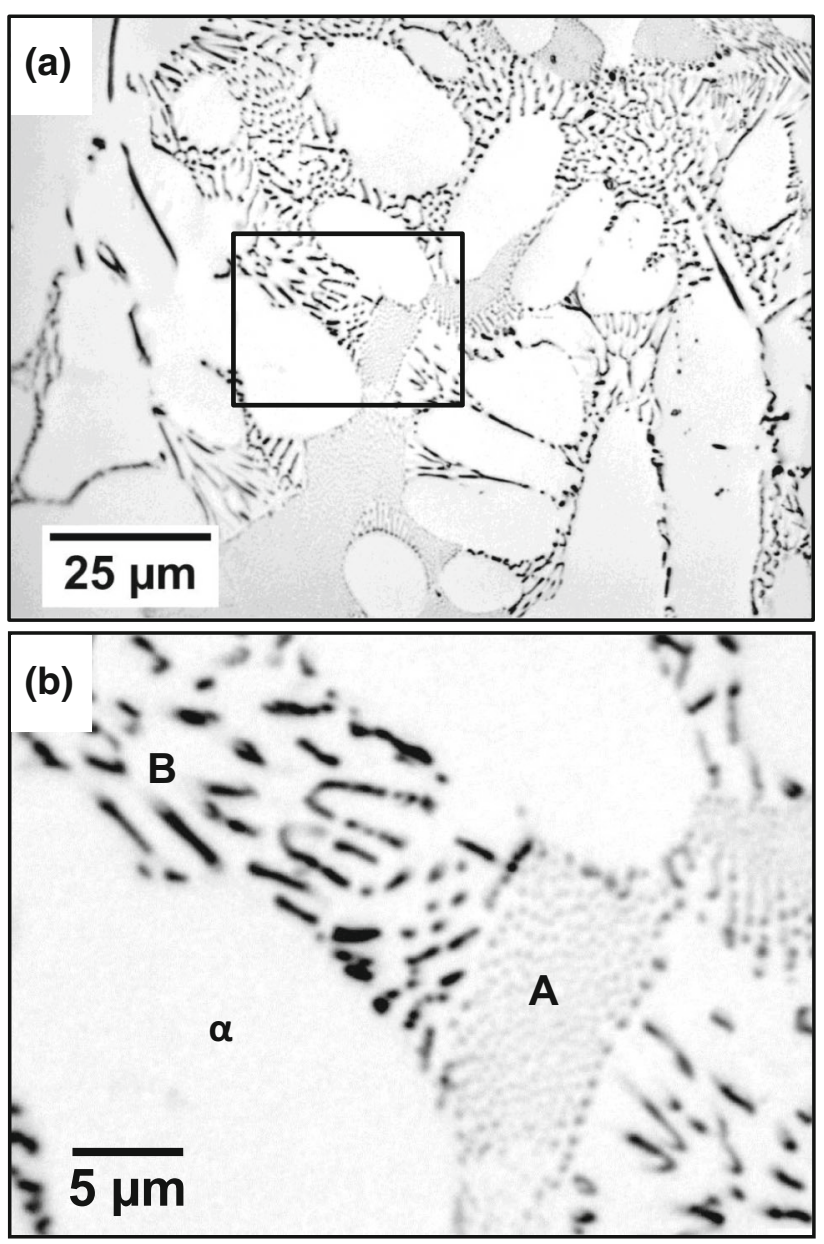

(c)

$25 \mu \mathrm{m}$

Fig. 1-(a) Optical micrograph of the as-cast sample, $(b)$ magnified area from (a) showing different phases present: $\alpha-\mathrm{Al}$, (A) $\mathrm{Al}+\mathrm{Al}_{6} \mathrm{Fe}$ eutectic, (B) $\mathrm{Al}+\mathrm{Al}_{3} \mathrm{Fe}$ eutectic and (c) HPT-processed for 75 revolutions.

HPT sample and by dashed lines for the aged samples. Each datum point represents an average of 12 measurements at equal distance from the disk center. Microhardness increases significantly over the as-cast level with increasing the equivalent strain. This is then followed by saturation of the hardness in the strain range beyond $\varepsilon \sim 200$. This trend is consistent with the

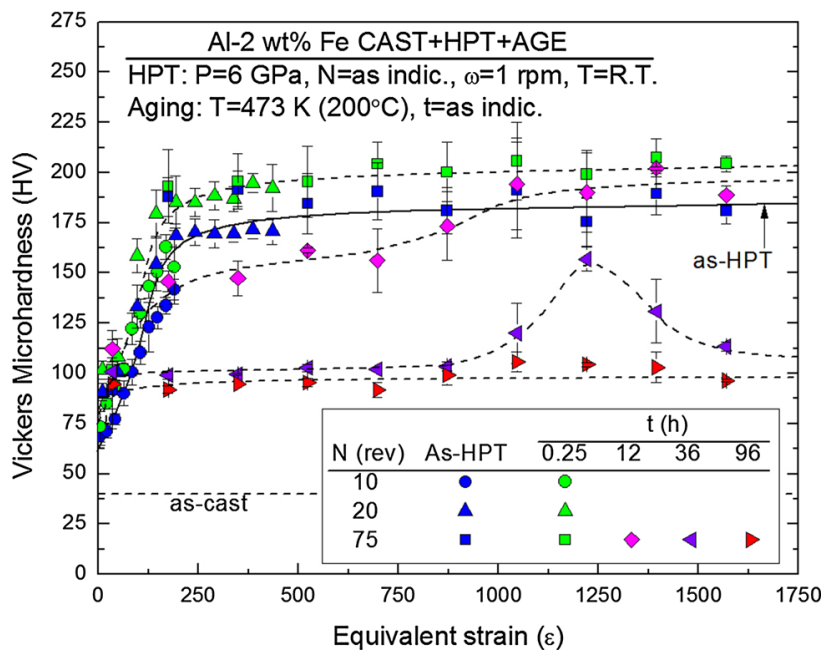

Fig. 2-Vickers microhardness plotted against equivalent strain for HPT-processed and aged samples at $473 \mathrm{~K}\left(200^{\circ} \mathrm{C}\right)$.

results reported earlier. ${ }^{[37]}$ After aging the samples for 0.25 hours, hardening occurs throughout the entire range of strain: the microhardness at the saturated level increases from $\sim 185 \mathrm{HV}$ after HPT to $\sim 205 \mathrm{HV}$ after the aging. When the samples processed for $N=75$ revolutions are further aged, the microhardness decreases with aging for 12, 36 and 96 hours. The decrease in the microhardness is not equal especially after aging for 12 and 36 hours: for the former aging, the decrease is more prominent in the strain range below 1000, and for the latter aging, it becomes further pronounced except for the strain range of $\varepsilon=1000$ to 1500 . The reason for this unexpected higher value of hardness at $\varepsilon=1250$ is still unclear. However, the microhardness decreases to a constant level $(\sim 100 \mathrm{HV})$ irrespective of the strained condition after prolonged aging for 96 hours (4 days), thus the difference in the aging behavior could be attributed to heterogeneous microstructures developed during the HPT processing. Loss in pressure to some extent, near the edges of the HPT die (sample is not in a completely constrained condition), could contribute to reduce the strain imposed to the near-edge region of the disk resulting in a slightly different aging behavior.

\section{Aging Behavior}

The results presented in Figure 2 indicate that the strain imposed by the HPT process has a strong effect on the aging behavior. In Figure 3, the microhardness is plotted against the aging time for two different temperatures: at $373 \mathrm{~K}$ and $473 \mathrm{~K}\left(100{ }^{\circ} \mathrm{C}\right.$ and $\left.200{ }^{\circ} \mathrm{C}\right)$ after processing for $N=10$ and $N=75$ revolutions, respectively. Each datum point corresponds to the average microhardness of six measurements taken from two different regions in the disks: Figure 3(a) at middistance between the disk center and the edge (i.e., $r=2.5 \pm 0.5 \mathrm{~mm}$ corresponding to $\varepsilon=100$ to 150 for $N=10$ and $\varepsilon=750$ to 1100 for $N=75)$ and Figure 3(b) from a region close to the edge $(r=4.5 \pm$ $0.5 \mathrm{~mm}$ corresponding to $\varepsilon=200$ to 250 for $N=10$ and $\varepsilon=1500$ to 2000 for $N=75$ ). 
The sample processed for $N=75$ and then aged at $473 \mathrm{~K}\left(200^{\circ} \mathrm{C}\right)$ exhibits the peak hardness after 0.25 hours for both the mid-distance from the disk center and near the edge. The hardness begins to decrease below the as-HPT level after 3 hours of aging at mid-distance from the center as shown in Figure 3(a) and after 12 hours of aging as shown in Figure 3(b). For the sample processed for $N=10$ and aged at $373 \mathrm{~K}$ $\left(100{ }^{\circ} \mathrm{C}\right)$, the peak-aged condition is reached after

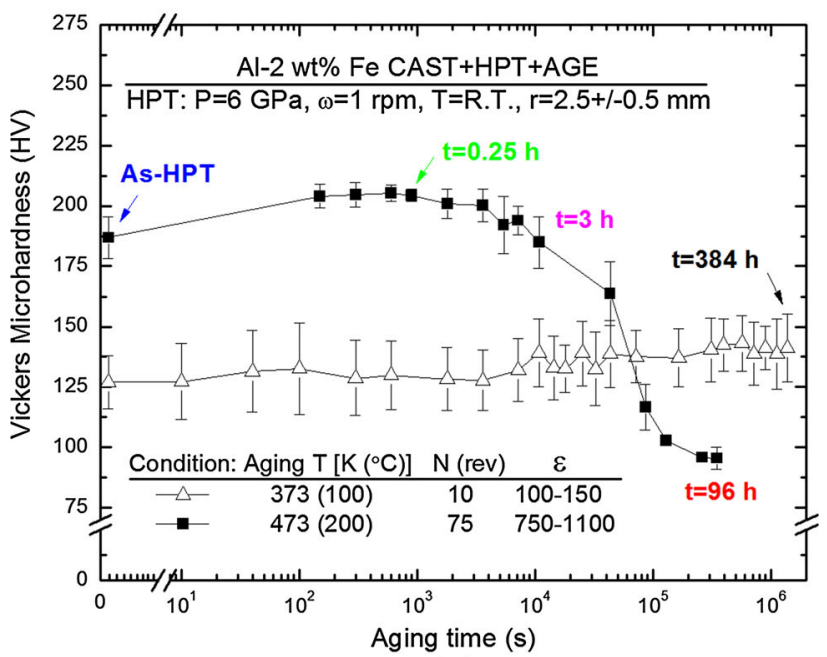

(a)

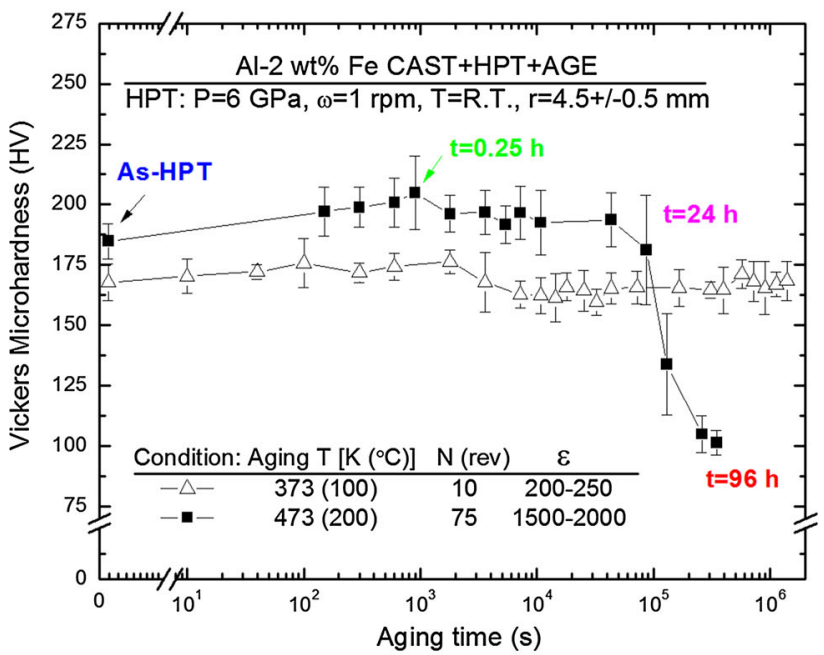

(b)

Fig. 3-Vickers microhardness plotted against aging time $(a)$ at distance of $2.5 \pm 0.5 \mathrm{~mm}$ and $(b) 4.5 \pm 0.5 \mathrm{~mm}$ from disk center.
3 hours of aging at mid-distances from the disk center and the hardness does not decrease even after prolonged aging. The peak hardness is reached after 0.5 hours at the disk edge followed by a slight decrease in the hardness.

Table I summarizes the maximum increase in hardness and the time to reach the peak-aged condition including additional data from samples processed for different conditions. The increase in hardness after aging the samples processed for equal numbers of revolutions is more pronounced when the samples are aged at $473 \mathrm{~K}$ $\left(200{ }^{\circ} \mathrm{C}\right)$. In this condition, the hardness peak occurs after 0.25 hours irrespective of the number of revolutions.

\section{Tensile Tests and Fractography}

Figure 4 shows the results of the tensile tests carried out on specimens extracted from the HPT-processed disks and after the aging treatments. The result of an ascast specimen is also included for comparison. Tensile strength is in good agreement with the hardness levels shown in Figure 2 through the relation as $\sigma \sim 3 \mathrm{HV}$, where $\sigma$ is the tensile strength and HV is the Vickers microhardness. ${ }^{[38]}$ The tensile strength increases to $\sim 500$, $\sim 550$ and $\sim 600 \mathrm{MPa}$ by HPT processing for $N=10$, 20 and 75 , respectively, as a result of the microstructure refinement. The additional increase in the tensile strength is also consistent with the hardness measurement after peak aging so that the tensile strength increases to $\sim 550, \sim 600$ and $\sim 700 \mathrm{MPa}$ by HPT processing for $N=10,20$, and 75 , respectively.

It is important to emphasize that processing by HPT not only increases the tensile strength but also retains excellent uniform elongation as high as $\sim 10$ pct in the sample processed for $N=10$ and $\sim 12$ pct in the sample processed for $N=20$ as shown in Figure 4. At this level of imposed strain, the material can still exhibit work-hardening during the tensile deformation due to the presence of finely dispersed second phase particles. ${ }^{[3,5]}$ It was shown in Figure 1(c) that significant fragmentation and dispersion of the original eutectic particles occurs after processing for $N=75$ revolutions. The change in particle distribution with increasing strain by HPT should have a strong effect on dislocation mobility during the tensile deformation. Accumulation of dislocations is enhanced at higher imposed strains, which in turn promotes localization of strain and necking to develop earlier, as observed in the as-HPT specimen from the sample processed for $N=75$ revolutions. This causes the uniform elongation in this sample

Table I. Maximum Increase in Hardness at Peak-Age and Time to Peak-Age

\begin{tabular}{|c|c|c|c|c|c|}
\hline \multicolumn{2}{|c|}{$\mathrm{Al}-2$ pct $\mathrm{Fe} \mathrm{CAST}+\mathrm{HPT}+\mathrm{AGE}$} & \multicolumn{2}{|c|}{$r=2.5 \pm 0.5 \mathrm{~mm}$} & \multicolumn{2}{|c|}{$r=4.5 \pm 0.5 \mathrm{~mm}$} \\
\hline$N($ rev $)$ & Aging $\mathrm{T}\left[\mathrm{K}\left({ }^{\circ} \mathrm{C}\right)\right]$ & $\Delta \mathrm{Hv}_{\text {peak }}(\mathrm{HV})$ & $t_{\text {peak }}(\min )$ & $\Delta \mathrm{Hv}_{\text {peak }}(\mathrm{HV})$ & $t_{\text {peak }}(\min )$ \\
\hline \multirow[t]{2}{*}{10} & $373(100)$ & 13 & 180 & 8 & 30 \\
\hline & $473(200)$ & 21 & 15 & 23 & 15 \\
\hline 20 & $473(200)$ & 19 & 15 & 21 & 15 \\
\hline 75 & $473(200)$ & 18 & 15 & 20 & 15 \\
\hline
\end{tabular}




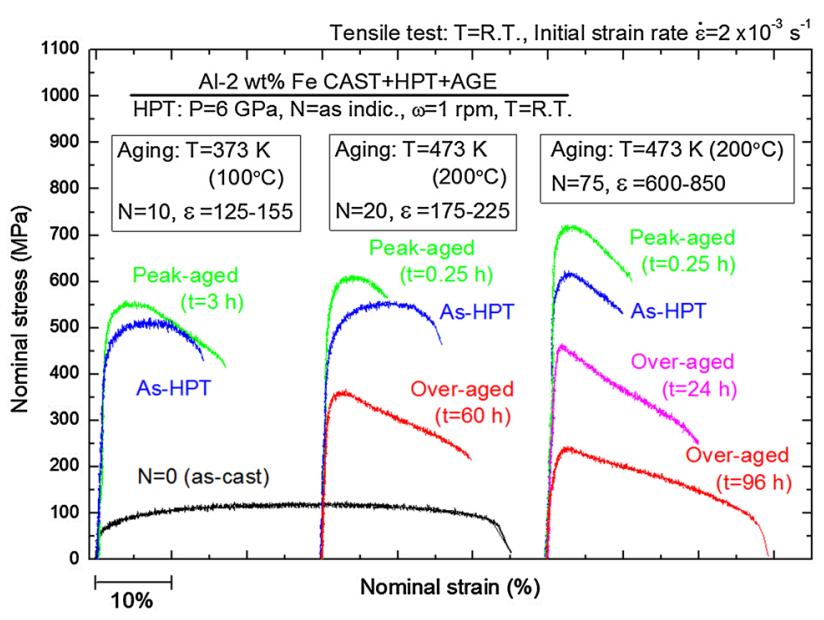

Fig. 4-Engineering stress-strain curves obtained by tensile tests using specimens extracted from the as-cast, as-HPT, and aged samples for different periods.

to drop to $\sim 3$ pct when compared to the as-HPT specimens processed for lower numbers of revolutions.

It is also apparent from Figure 4 that there is a tradeoff relation between age hardening and uniform elongation, even after prolonged aging. The yield stress increases after aging the samples processed for $N=10$ and $N=20$ revolutions to the peak-aged condition, which suggests that the localization of strain and reduction of the work-hardening ability may occur in these samples due to the presence of high concentration of precipitates. The uniform elongation in the peak-aged state is $\sim 7.5$ pct for the sample processed for $N=10$ and $\sim 6$ pct for the sample processed for $N=20$. This phenomenon is less evident for the sample processed for $N=75$, where the uniform elongation is $\sim 4$ pct, practically the same as in the as-HPT case. The state of the microstructure after HPT and its effect on the precipitation behavior should play an important role in the ductility of this material after aging.

Several studies have reported successful combinations of strengthening by grain refinement and by fine precipitation in Al 7000 series produced by cryomilling, hot isostatic pressing and extrusion followed by artificial aging, ${ }^{[39-41]}$ and in Al 6022, ${ }^{[42]} \mathrm{Al} 2091^{[42,43]}$ Al-4 pctCu ${ }^{[44]}$ processed by HPT and aging, and more recently in $\mathrm{Al} 7075^{[45]}$ after processing by high-pressure sliding (HPS) and aging. All of these studies have shown significant differences between a coarse-grained structure and an ultrafine-grained structure, and a strong correlation with the dislocation substructures as sites for heterogeneous nucleation of precipitates. The result from the tensile tests in this study shows large potential to control the microstructure of the Al-Fe alloy by optimizing the combination of deformation and aging treatment. The aging treatment may be optimized accordingly to improve the uniform elongation. Nonetheless the levels of strength and elongation achieved in this study are well comparable to or even superior to commercial high-strength alloys such as Al 2024 and 7075 alloys. ${ }^{[46]}$

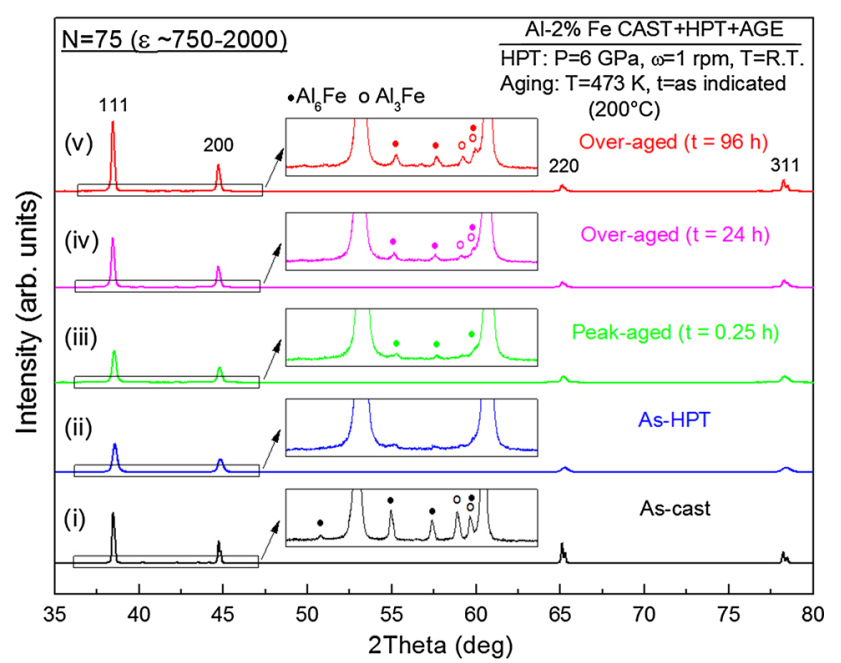

(a)

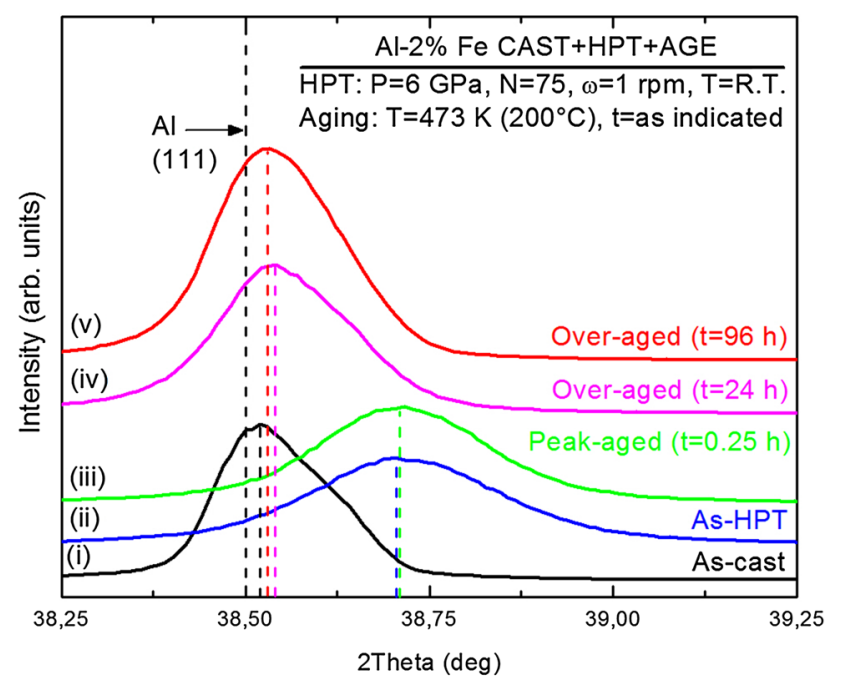

(b)

Fig. 5-(a) XRD profiles: as-cast, HPT-processed and aged at $473 \mathrm{~K}$ $\left(200{ }^{\circ} \mathrm{C}\right)$ for different time intervals and $(b)$ enlarged view showing shift in $(111)_{\alpha}$ peak.

\section{E. XRD Analysis for Dissolution and Precipitation}

Figure 5 shows the XRD profiles from the $3 \mathrm{~mm}$ disks extracted from the as-cast material, after processing by HPT for $N=75$ and after aging at $473 \mathrm{~K}$ $\left(200{ }^{\circ} \mathrm{C}\right)$ for selected periods where the range of equivalent strain covered by the selected specimens is $\varepsilon$ $\sim 750$ to 2000. Figure 5(a) includes enlarged profiles between the fundamental (111) and (200) reflections to show changes in the superlattice reflections from the second phases with HPT straining and with aging treatment. Their low relative intensities to the fundamental reflections are because their volume fraction is low. The strongest peaks of both $\mathrm{Al}_{6} \mathrm{Fe}$ and $\mathrm{Al}_{3} \mathrm{Fe}$ phases were detected in the as-cast state, according to powder diffraction data as shown in spectrum (i) in Figure 5(a). After the HPT processing, their intensity decreases almost to the background level, as shown by the transition from profile (i) to (ii), which suggests that dissolution of $\mathrm{Fe}$ in the matrix occurred. 


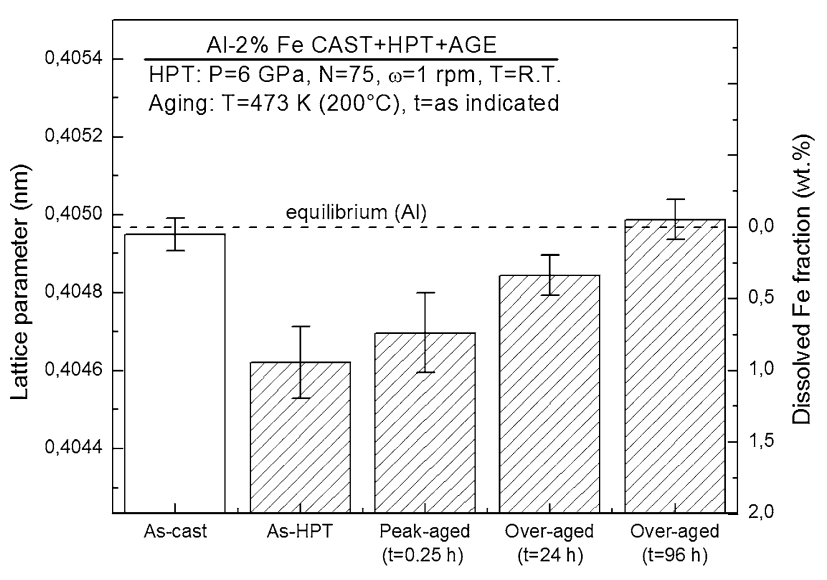

Fig. 6- Change in lattice parameter and fraction of dissolved $\mathrm{Fe}$ with respect to HPT processing and aging time.

Figure 5(b) shows an enlarged view of the (111) peak after offset correction using $\mathrm{LaB}_{6}$. The reference position according to powder diffraction data of pure $\mathrm{Al}$ is shown with the dotted line. The peak for the as-cast condition shows a slight shift to a higher Bragg angle with respect to the reference position. The peak position significantly shifted to a larger angle after HPT processing for $N=75$. No appreciable change in the peak position occurred from the position for the as-HPT value after the 0.25 hours aging. Further aging after HPT for 24 and 96 hours resulted in the corresponding peak positions to shift back closer to the value for the as-cast state. The peak shift to a higher Bragg angle after HPT processing is attributed to the change in the lattice constant of the matrix as a result of dissolution of $\mathrm{Fe}$, as it was determined in the work by rapid solidification. ${ }^{[20-23]}$ The detailed procedures to estimate the amount of dissolved $\mathrm{Fe}$ from the XRD profiles are shown in the "Appendix".

Figure 6 shows the variation of lattice parameter with HPT straining and with aging. The corresponding amount of dissolved $\mathrm{Fe}$ in the matrix is shown on the secondary axis in weight fraction. The error bars correspond to the 95 pct confidence intervals from the least squares method used to fit the data in Figure A1. For the as-cast state, it is confirmed that $\mathrm{Fe}$ content is negligible within experimental error as expected from the equilibrium phase diagram. The dissolution of $\mathrm{Fe}$ reaches to $0.95 \mathrm{pct}$ after processing for $N=75$. An additional estimation shows that dissolution is $0.46 \mathrm{pct}$ after HPT processing for $N=20$. Thus, a significant amount of supersaturation is achieved so that $\sim 25$ and $\sim 50 \mathrm{pct}$ of the total content of $\mathrm{Fe}$ are dissolved in the samples processed after $N=20$ and $N=75$, respectively. The undissolved fraction of Fe-containing phases has been fragmented to sizes below the resolution of the $\mathrm{XRD}$, and thus only a trace of the corresponding peaks is visible in the enlarged region of profile (ii) in Figure 5(a). The results in this study are consistent with the previous report. ${ }^{[37]}$ Aging to the peak condition releases a relatively small fraction of $\mathrm{Fe}$ from the supersaturated state: $\sim 0.40$ pct of $\mathrm{Fe}$ remains in the matrix after processing for $N=20$ and $\sim 0.74$ pct for
$N=75$. The Fe content in the matrix decreases to $\sim 0.35$ pct after 24 hours aging and a complete decomposition occurs after 96 hours aging.

Precipitation kinetics in this study may be evaluated using the following equation and compared with past reports for the recrystallized and cold-worked Al-Fe alloys: $:^{[47,48]}$

$$
x=\frac{c-c_{\mathrm{e}}}{c_{0}-c_{\mathrm{e}}}
$$

where $x$ is the rate of $\mathrm{Fe}$ removal from saturated state, $c_{\mathrm{e}}$ is the equilibrium concentration at the aging temperature, $c_{0}$ is the initial concentration, and $c$ is the concentration of $\mathrm{Fe}$ in supersaturation at a given time. The values of $c_{0}$ and $c$ are as determined from the XRD results in Figure 6. Taking $c_{0}$ as the concentration of $\mathrm{Fe}$ after HPT processing, it follows that $x=0.88$ for the sample processed through $N=20$ and $x=0.77$ for the sample processed through $N=75$ after the 0.25 hours aging (peak-aged condition). For the over-aged condition, $x=0.35$ after 24 hours aging and $x=0$ after 96 hours aging. A similar rate of Fe removal, namely $x=0.85$ in Reference 47 , is only achieved after 0.25 hours aging at a temperature of $623 \mathrm{~K}\left(350^{\circ} \mathrm{C}\right)$ for the cold-worked structure and after at least 3 hours aging at $723 \mathrm{~K}\left(450{ }^{\circ} \mathrm{C}\right)$ for the recrystallized structure. In this study, the temperature is significantly lower as $473 \mathrm{~K}\left(200{ }^{\circ} \mathrm{C}\right)$ but nevertheless, the equivalent $\mathrm{Fe}$ removal rate is obtained. It is considered that this is attributed to the generation of a high density of lattice defects such as vacancies, dislocations, and grain boundaries that could enhance the Fe diffusivity. ${ }^{[99]}$

\section{F. Microstructure Observation by TEM}

Figure 7 shows TEM dark-field images comparing the microstructures from the samples processed by HPT for $N=20$ before and after aging to the peak condition at $473 \mathrm{~K}\left(200{ }^{\circ} \mathrm{C}\right)$. The selected area electron diffraction (SAED) patterns shown on the right were obtained from a region of $\sim 1.5 \mu \mathrm{m}$ in size. The fundamental diffraction spots form along rings as delineated by fine yellow real lines in each SAED pattern. The expected diffraction rings of $\mathrm{Al}_{3} \mathrm{Fe}$ are also drawn, according to diffraction intensity, in the corresponding diffraction patterns as fine red real lines. It can be seen that several diffracted beams match the $\mathrm{Al}_{3} \mathrm{Fe}$ diffraction within the first $\mathrm{Al}$ fundamental ring. The dark-field images in Figures 7(a) and (b) are taken from diffracted beams between the fundamental (111) and (200) reflections, respectively, by selecting an objective aperture as circled in the SAED patterns. The image in Figure 7(a) shows that the microstructure after processing by HPT for $N=20$ is composed of equiaxed, ultrafine-grained structures with a mean grain size of $\sim 130 \mathrm{~nm}$. Grains with high misorientations can be appreciated with the diffracted beams distributed along the fundamental rings in the SAED pattern. Figure 7(b) shows that the grain size at the peak-aged condition is $\sim 160 \mathrm{~nm}$ and thus the ultrafine-grained structure having high angles of misorientations remains almost unchanged. 

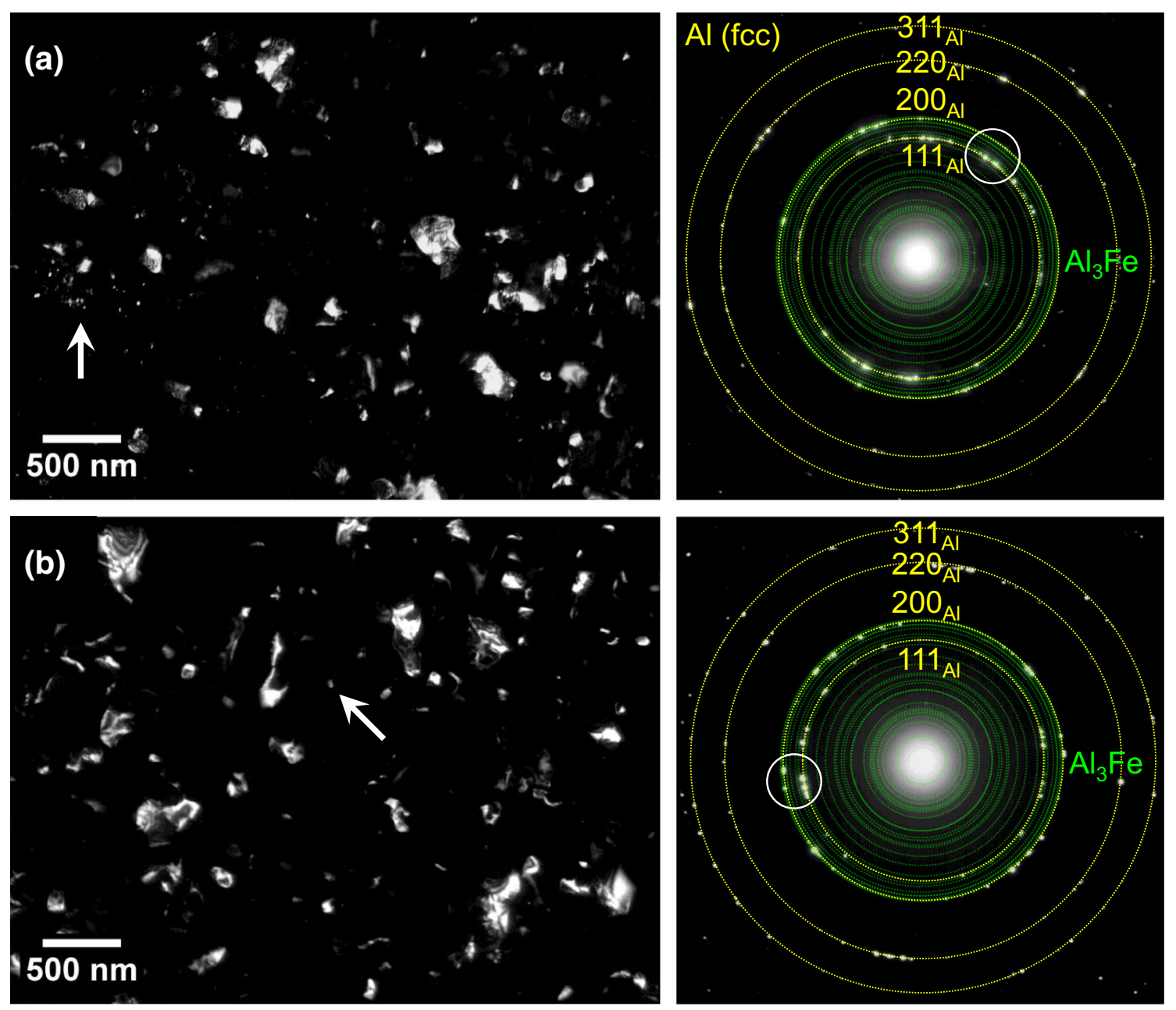

Fig. 7- (a) TEM dark-field images (left) and SAED patterns (right) from samples processed through $N=20$ revolutions and (b) processed through $N=20$ revolutions and peak aging. Dark-field images obtained from selected beams as shown by circles in corresponding SAED patterns including diffractions from both matrix and second phase particles, where particles are marked by arrows in dark-field images.

As it was observed in the XRD results in Figure 5, the strongest diffraction of intermetallics stays close to the $\mathrm{Al}(111)$ and (200) fundamental reflections, and thus the diffraction from particles of eutectic origin exists within the selected apertures used to generate the dark-field images. A very fine dispersion of intermetallic particles can be determined in the dark-field images as pointed by arrows in Figure 7(a). It is most likely that this dispersion significantly contributes to grain refinement and to the strengthening of this material after HPT processing. ${ }^{[37]}$ The diffraction from such particles is also observed in the sample after aging as pointed by an arrow in the dark-field image in Figure 7(b). However, it is not clear from the images if the particles correspond to dispersion from the initial eutectics or precipitation from the solid solution. Nonetheless, the superlattice spots from these particles are consistent with the reflections from $\mathrm{Al}_{3} \mathrm{Fe}$ (or $\mathrm{Al}_{6} \mathrm{Fe}$ ), as observed in the corresponding SAED patterns of Figure 6. A detailed study is in progress for this clarification using highresolution lattice image analysis and STEM-HAADF for identification of precipitates and dispersed fragmented particles.
Figure 8 shows the succession of TEM dark-field images taken from the samples processed by HPT for $N=75$ and aged at $473 \mathrm{~K}\left(200^{\circ} \mathrm{C}\right)$ for $0.25,24$, and 96 hours as corresponding to spectra (ii) to (v) in Figure 5. The diffracted beams from fundamental and superlattice spots used to form the dark-field images are selected in a manner similar to Figure 7 , as circled in each of the SAED patterns in the corresponding insets in Figure 8. The average grain size slightly decreased from $\sim 130$ to $\sim 120 \mathrm{~nm}$ when the revolution of HPT processing increases from $N=20$ to $N=75$ according to Figures 7(a) and 8(a), respectively. The grain size increases from $\sim 120$ to $\sim 140 \mathrm{~nm}$ by aging to the peak condition for 0.25 hours, and to $\sim 180 \mathrm{~nm}$ after aging for 24 hours as shown by the images in Figures 8(b) and (c), respectively. This state of the microstructure represents the condition where the hardness decreases below the asHPT level, according to Figure 3(b). The average grain size reaches to $\sim 400 \mathrm{~nm}$ after aging for 96 hours (4 days) as shown in Figure 8(d). The microstructure evolution with aging is summarized such that recovery dominates up to the peak condition as shown in Figures 7(b) and 8 (b) and some grain growth occurs, while the recovery is 

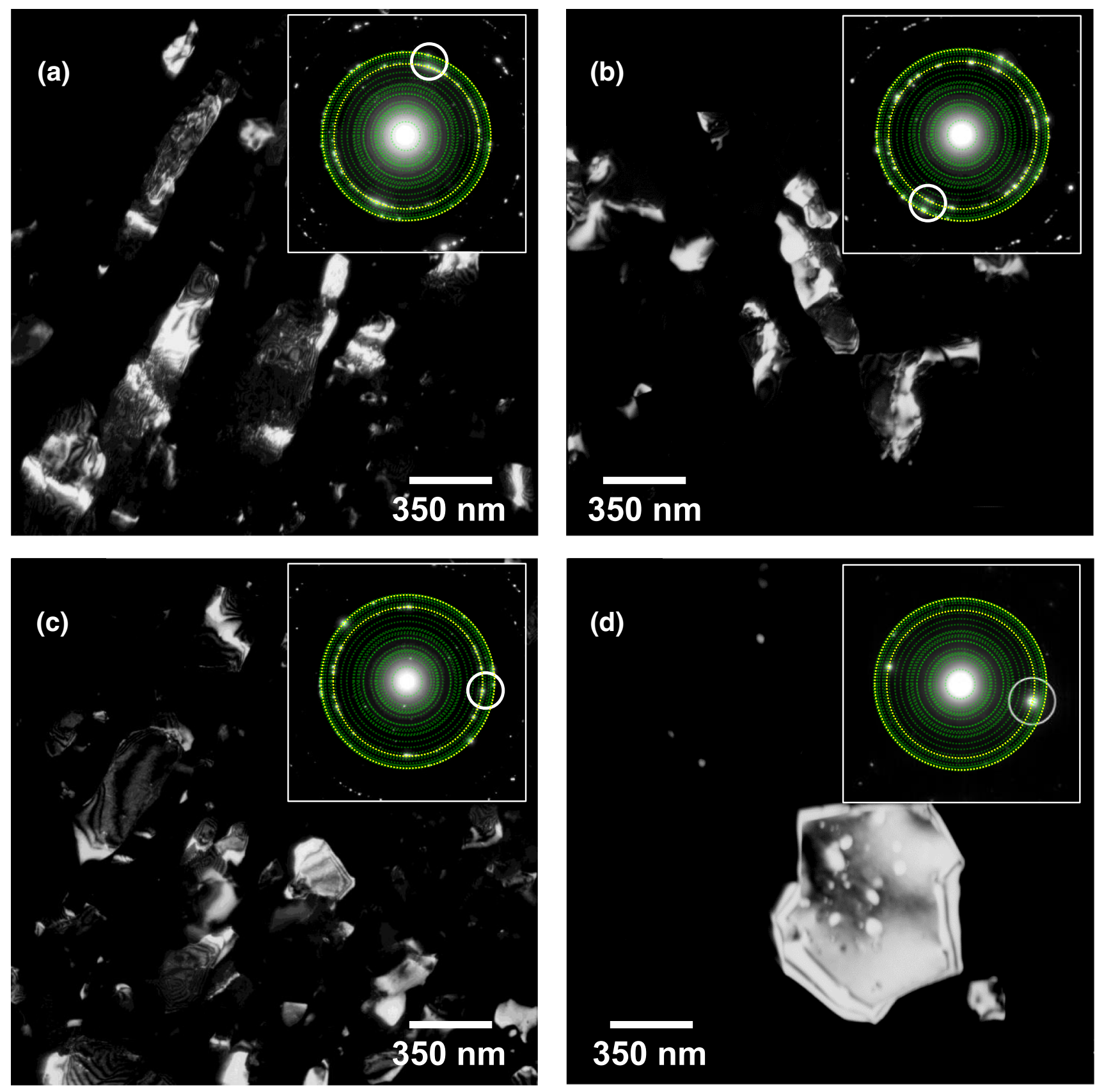

Fig. 8-(a) TEM dark-field images (left) and SAED patterns (as insets) from sample processed through $N=75$ revolutions and processed through $N=75$ revolutions and aged at $473 \mathrm{~K}\left(200^{\circ} \mathrm{C}\right)$ for: $(b) 0.25 \mathrm{~h},(c) 24 \mathrm{~h}$ and $(d) 96 \mathrm{~h}$. Dark-field images obtained from selected beams as shown by circles in corresponding SAED patterns.

still in progress. As a result, the hardness starts to decrease sometime between 3 and 12 hours as shown in Figure 3(a) for the sample processed by HPT for $N=75$. Grain growth becomes more intensive after aging for over 24 hours and the microstructure develops into a fully equiaxed structure as in Figure 8(d).

\section{G. Observation and Analysis of Precipitates}

Figure 9 shows TEM bright-field and dark-field images of the samples processed for $N=75$ and aged at different states corresponding to spectra (iii), (iv), and (v) in Figure 5. The images are now shown in higher magnifications to detail for grains and precipitates. The bright-field image in Figure 9(a) confirms that the ultrafine grained structure was retained after 0.25 hours of aging as observed in Figure 8(b). The dark-field image in Figure 9(a) was obtained using a (200) reflection as circled in the corresponding SAED pattern. Several precipitates with sizes smaller than $10 \mathrm{~nm}$ are visible within the grain as marked $\mathbf{P}$ with the two arrows. The image in Figure 9(b) corresponds to the over-aged state after 24 hours, and shows that the size of the precipitates within a grain is more or less 

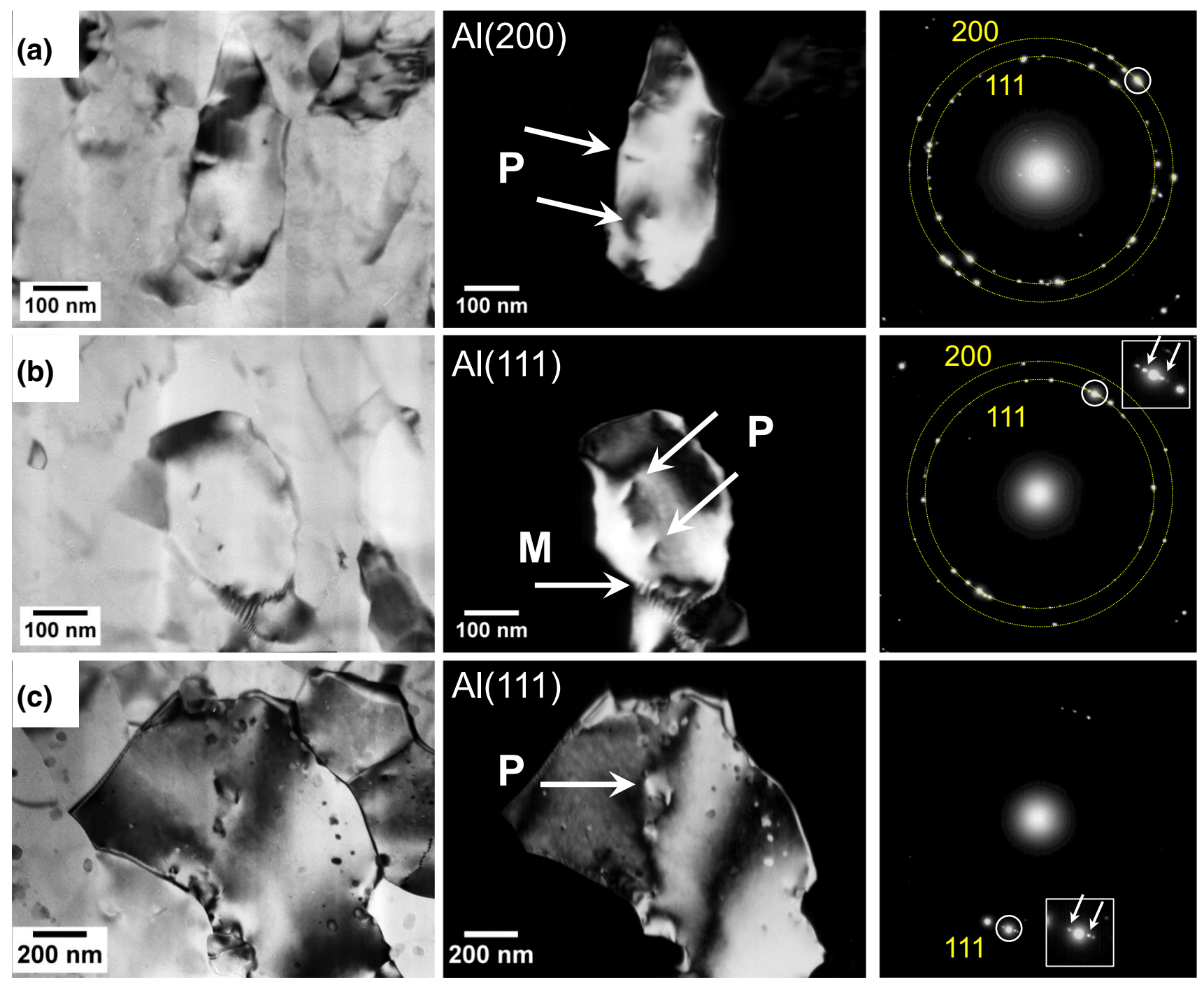

Fig. 9-TEM bright-field (left), dark-field images (center) and corresponding SAED patterns (right) from sample processed through $N=75$ revolutions and aged at $473 \mathrm{~K}\left(200^{\circ} \mathrm{C}\right)$ for $(a) 0.25 \mathrm{~h},(b) 24 \mathrm{~h}$ and $(c) 96 \mathrm{~h}$. Dark-field images were taken with beams selected by circles in SAED patterns. Superlattice reflections from precipitates are visible as indicated by arrows in enlarged views of SAED patterns in (b) and (c).

similar to the one observed in the peak-aged state. Occasionally, coarser precipitates are observed on the grain boundary as marked by an arrow $\mathbf{M}$ near the Moiré pattern other than particles within a grain as indicated by the two arrows $\mathbf{P}$. After 96 hours aging to well over-aged state, the sample exhibits a recrystallized structure with the grain size increased and grain boundaries well-defined as shown by the image in Figure 9(c). Many globular precipitates with their sizes of $\sim 30$ to $50 \mathrm{~nm}$ are observed throughout the matrix. The precipitates marked by arrows $\mathbf{P}$ in the dark-field images of Figures 9(a) and (b) generate typical strain contrasts. This suggests that there is some coherency between the matrix and precipitates in the aged states of Figures 9(a) and (b), but the coherency is lost in the well over-aged state of Figure 9(c).

The characteristics of the fine precipitation within the small grains discussed in this section can account for the increase in hardness with aging. Shortly after reaching the peak state, the hardness decreases to a level below the as-HPT state. This aging behavior should be associated with the fine precipitation within the small grains from an initial stage of aging to the peak aging and subsequently in the later stage with the growth and/ or the phase change in the precipitates. According to the XRD analysis shown in Figure 5, the precipitates were determined to be either $\mathrm{Al}_{6} \mathrm{Fe}$ or $\mathrm{Al}_{3} \mathrm{Fe}$. The superlattice spots are detected near the fundamental in the SAED patterns in Figures 9(b) and (c) and these are more clearly indicated by arrows in enlarged views in the insets. The difficulty of unequivocally identifying the precipitates from the SAED patterns in Figure 9 arises due to the similar lattice spacing between $\mathrm{Al}_{3} \mathrm{Fe}$ and $\mathrm{Al}_{6} \mathrm{Fe}$. More so, it was not possible to make a clear distinction which was the dominant phase at the peak hardness because both phases were present at the initial state after casting. It was reported for solid solutions of $\mathrm{Al}-0.05 \mathrm{pctFe}^{[47]}$ and $\mathrm{Al}-0.03 \mathrm{pctFe}^{[48]}$ alloys that precipitation from recrystallized structures is mostly $\mathrm{Al}_{3} \mathrm{Fe}$, whereas in the deformed structures by cold rolling, 
$\mathrm{Al}_{6} \mathrm{Fe}$ always precipitates first. A similar conclusion was reported for precipitation from supersaturated solid solutions obtained by RQ ${ }^{[21]}$ However, the case may be, the differences in $\mathrm{Fe}$ concentration in solid solution, as shown by the XRD results in Figure 6, as well as the size/distribution of precipitates and undissolved $\mathrm{Al}_{3} \mathrm{Fe}$ particles, both of which have a strong interaction with dislocations, should play also a major role in terms of the ductility of the samples before and after aging.

\section{SUMMARY AND CONCLUSIONS}

This report has shown that age hardening is achieved in a traditionally insoluble system by formation of a supersaturated solid solution of Fe in Al via the solidstate processing by HPT. Microstructures are controlled by precipitation of dissolved $\mathrm{Fe}$ as fine intermetallic particles within the ultrafine-grained matrix, which is not common in the Al-Fe system under equilibrium or industrial processing conditions. The following conclusions are drawn from the results presented in this study:

1. The initial microstructure was composed of $\alpha$-Al dendrites, a metastable eutectic phase composed of $\mathrm{Al}_{6} \mathrm{Fe}$ fibers with 150 to $200 \mathrm{~nm}$ in diameter, and the coarser equilibrium eutectic composed of $\mathrm{Al}_{3} \mathrm{Fe}$ discontinuous lamellar structures with widths smaller than $\sim 1.5 \mu \mathrm{m}$.

2. As a result of the HPT processing, the intermetallic structures in the initial eutectics were partially dissolved up to a maximum of $\sim 1$ pct $\mathrm{Fe}$ in supersaturated solution and otherwise fragmented and dispersed in the $\mathrm{Al}$ matrix. The particles have a wide range of distribution in sizes at the nanometer level.

3. The grain size of the Al matrix was reduced to $\sim 120 \mathrm{~nm}$ at the saturated state. This grain size was rather stable up to subsequent aging at $473 \mathrm{~K}$ $\left(200{ }^{\circ} \mathrm{C}\right)$ such that the grain growth was $\sim 140 \mathrm{~nm}$ for aging up to 0.25 hours and $\sim 180 \mathrm{~nm}$ for 24 hours. However, aging for 96 hours led to grain growth to $\sim 400 \mathrm{~nm}$ although it is still in the range of ultrafine-grained size.

4. The high strength after HPT processing was achieved to a maximum UTS of $\sim 600 \mathrm{MPa}$ through a combination of the structure refinement in the matrix grains and intermetallic particles.

5. Age hardening occurred to a peak hardness of $205 \mathrm{HV}$ within 0.25 hours at $473 \mathrm{~K}\left(200{ }^{\circ} \mathrm{C}\right)$ and to a maximum UTS of $\sim 700 \mathrm{MPa}$ via precipitation of dissolved $\mathrm{Fe}$ in a form of nano-sized $\mathrm{Al}_{6} \mathrm{Fe}$ and $\mathrm{Al}_{3} \mathrm{Fe}$ particles with $\sim 10 \mathrm{~nm}$ in size. Such fine precipitates occurred within the ultrafine grains but some on/near the grain and subgrain boundaries.

6. The uniform elongation exceeds $\sim 12$ pct even at intermediate levels of imposed strain by HPT, but it decreased to $\sim 6$ pct with the aging treatment. However, the combinations of strength and elongation achieved in this study are comparable to those of high strength commercial Al alloys.

\section{ACKNOWLEDGMENTS}

This study was carried out as a part of a materials development program in the Japan Aluminum Association. The authors thank Dr. Seungwon Lee and Dr. Yoshifumi Ikoma for their assistance in this study. One of the authors (JC) thanks the Ministry of Education, Culture, Sports, Science and Technology (MEXT) of Japan for a PhD scholarship. This work was supported in part by Japan Science and Technology Agency (JST) under Collaborative Research Based on Industrial Demand "Heterogeneous Structure Control: Toward Innovative Development of Metallic Structural Materials", in part by the Light Metals Educational Foundation of Japan, in part by a Grant-in-Aid for Scientific Research from the Ministry of Education, Culture, Sports, Science and Technology of Japan in the Innovative Area "Bulk Nanostructured Metals" 22102004.

\section{APPENDIX}

Figure A1 shows the Nelson-Riley plots used to determine the lattice constant using the extrapolation technique from the linear-fit of the data. A number of sources of error in the determination of the lattice constant, such as X-ray absorption in the specimen can be compensated by this method. The Nelson-Riley parameter is calculated for each diffraction peak according to the following function of the diffraction angle $\theta$, after correction using $\mathrm{LaB}_{6}$ and removing the contribution from the $\mathrm{K} \alpha_{2}$ radiation: ${ }^{[50]}$

$$
\frac{\Delta a}{a}=k\left(\frac{\cos ^{2} \theta}{\sin \theta}+\frac{\cos ^{2} \theta}{\theta}\right),
$$

where $a$ is the lattice constant and $K$ is a constant. The lattice parameter for each reflection is calculated using the Bragg Law for the cubic lattice, where $h, k$, and $l$

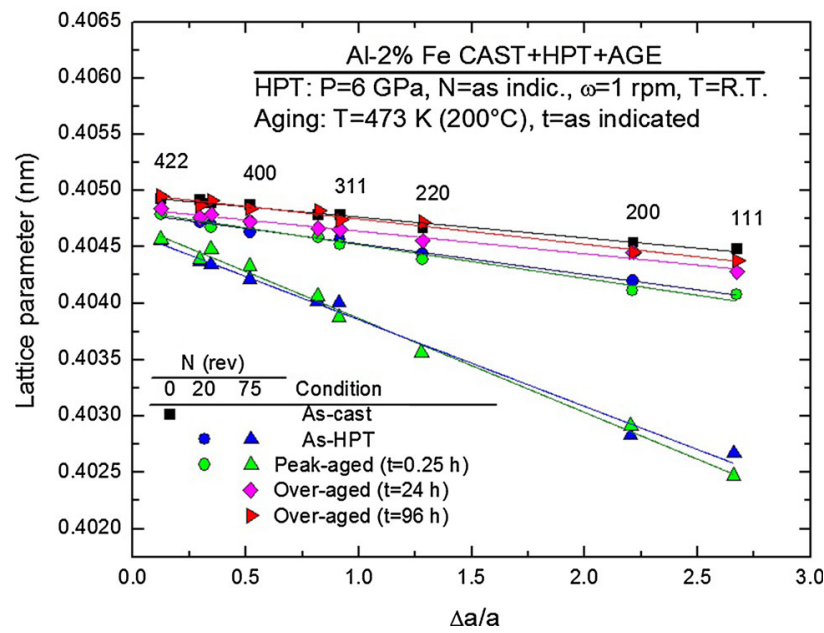

Fig. A1-Nelson-Riley plots obtained from XRD peak analysis. 
correspond to the Miller indices and $\lambda_{\mathrm{Cu}}$ is the wavelength of the $\mathrm{CuK} \alpha_{1}$ radiation $(1.540598 \AA)^{[50]}$

$$
a=\frac{\lambda_{\mathrm{Cu}}}{2 \sin \theta} \sqrt{h^{2}+k^{2}+l^{2}}
$$

The true lattice parameter of the specimen can be read from the intercept of each plot in Figure A1. The atomic concentration of $\mathrm{Fe}$ in solid solution $c$ can be estimated from the lattice constant using the following relation determined from a model of nearest neighbor interatomic spacing for supersaturated solid solutions of transition metals in $\mathrm{Al}^{[23]}$

$$
c=\frac{a_{\mathrm{Al}}-a}{2 \sqrt{2}\left(S_{\mathrm{Al}-\mathrm{Fe}}-S_{\mathrm{Al}-\mathrm{Al}}\right)}[\text { at. pct }],
$$

where $a_{\mathrm{Al}}$ is the lattice constant of pure $\mathrm{Al}$ and $s_{\mathrm{Al}-\mathrm{Fe}}$ and $s_{\mathrm{Al}-\mathrm{Al}}$ the mean interatomic spacings between the $\mathrm{Al}$ and $\mathrm{Fe}$ and $\mathrm{Al}$ and $\mathrm{Al}$ in the solid solution, which have been approximated from the bond lengths in $\mathrm{Al}_{6} \mathrm{Fe}{ }^{[8]}$ This relationship was verified experimentally for complete supersaturated solutions of up to 4.5 at. pet Fe in $\mathrm{Al}$ obtained by rapid solidification. ${ }^{[23]}$

\section{REFERENCES}

1. R.Z. Valiev, R.K. Islamgaliev, and I.V. Alexandrov: Prog. Mater Sci., 2000, vol. 45, pp. 103-89.

2. R.Z. Valiev, Y. Estrin, Z. Horita, T.G. Langdon, M.J. Zehetbauer, and Y.T. Zhu: JOM, 2006, vol. 58, pp. 33-39.

3. Y. Estrin and A. Vinogradov: Acta Mater., 2013, vol. 61, pp. 782 817.

4. A.P. Zhilyaev and T.G. Langdon: Prog. Mater. Sci., 2008, vol. 53, pp. 893-979.

5. I. Sabirov, M.Y. Murashkin, and R.Z. Valiev: Mater. Sci. Eng., A, 2013, vol. 560, pp. 1-24.

6. P.J. Black: Acta Crystallogr., 1955, vol. 8, pp. 43-48.

7. P.J. Black: Acta Crystallogr., 1955, vol. 8, pp. 175-82.

8. L.K. Walford: Acta Crystallogr., 1965, vol. 18, pp. 287-91.

9. R.M.K. Young and T.W. Clyne: Scripta Metall., 1981, vol. 15, pp. 1211-16.

10. P. Skjerpe: Metall. Trans. A, 1987, vol. 18A, pp. 189-200.

11. P. Skjerpe: Acta Crystallogr. B, 1988, vol. 44, pp. 480-86.

12. S.D. Forder, J.S. Brooks, and P.V. Evans: Scripta Mater., 1996, vol. 35 , pp. 1167-73.

13. N.A. Belov, A.A. Aksenov, and D.G. Eskin: Iron in Aluminum Alloys: Impurity and Alloying Element, 1st ed., Taylor and Francis, London, 2002, pp. 1-7.

14. C.M. Adam and L.M. Hogan: Acta Metall., 1975, vol. 23, pp. 345-54.

15. I.R. Hughes and H. Jones: J. Mater. Sci., 1976, vol. 11, pp. 178193.

16. I.R. Hughes and H. Jones: J. Mater. Sci., 1977, vol. 12, pp. 323 33

17. C.M. Adam and L.M. Hogan: J. Aust. Inst. Met., 1972, vol. 17, p. 81.

18. C.M. Adam and J.A. Eady: Acta Metall., 1979, vol. 27, pp. 79-87.

19. J. Strid, D.A. Porter, and K.E. Easterling: Mater. Sci. Technol., 1985, vol. 1, pp. 161-66
20. A. Tonejc and A. Bonefacic: J. Appl. Phys., 1969, vol. 40, pp. 41920.

21. A. Tonejc: Metall. Trans., 1971, vol. 2, pp. 437-40.

22. H. Jones: Mater. Sci. Eng. A, 1969, vol. 5, pp. 1-18.

23. H. Jones: Scripta. Metall., 1983, vol. 17, pp. 97-100.

24. D. Kunstelj and A. Bonefacic: Metallography, 1969, vol. 2, pp. 329-36.

25. D. Kunstelj and A. Bonefacic: Metallography, 1970, vol. 3, pp. 7987.

26. M.H. Jacobs, A.G. Doggett, and M.J. Stowell: J. Mater. Sci., 1974, vol. 9, pp. 1631-43.

27. G. Thursfield and M.J. Stowell: J. Mater. Sci., 1974, vol. 9, pp. $1644-60$.

28. J.D. Cotton and M.J. Kaufman: Metall. Trans. A, 1991, vol. 22A, pp. 927-34.

29. D.K. Mukhopadhyay, C. Suryanarayana, and F.H. Froes: Scripta Metall. Mater., 1994, vol. 31, pp. 333-38.

30. D.K. Mukhopadhyay, C. Suryanarayana, and F.H. Froes: Metall. Mater. Trans. A, 1995, vol. 26A, pp. 1939-46.

31. F. Cardellini, V. Contini, and G. Mazzone: J. Mater. Sci., 1996, vol. 31, pp. 4175-80.

32. F. Cardellini, V. Contini, R. Gupta, G. Mazzone, A. Montone, A. Perin, and G. Principi: J. Mater. Sci., 1998, vol. 33, pp. 2519-27.

33. T.T. Sasaki, T. Ohkubo, and K. Hono: Acta Mater., 2009, vol. 57, pp. 3529-38.

34. S.S. Nayak, M. Wollgarten, J. Banhart, S.K. Pabi, and B.S. Murty: Mater. Sci. Eng. A, 2010, vol. 527, pp. 2370-78.

35. O.N. Senkov, F.H. Froes, V.V. Stolyarov, R.Z. Valiev, and J. Liu: Nanostruct. Mater., 1998, vol. 10, pp. 691-98.

36. V.V. Tcherdyntsev, S.D. Kaloshkin, D.V. Gunderov, E.A. Afonina, I.G. Brodova, V.V. Stolyarov, Y.V. Baldokhin, E.V. Shelekhov, and I.A. Tomilin: Mater. Sci. Eng. A, 2004, vols. 375-377, pp. 888-93.

37. J.M. Cubero-Sesin and Z. Horita: J. Mater. Sci., 2013, vol. 48, pp. 4713-22.

38. D. Tabor: Rev. Phys. Techol., 1970, vol. 1, pp. 145-79.

39. T. Hu, K. Ma, T.D. Topping, J.M. Schoenung, and E.J. Lavernia: Acta Mater., 2013, vol. 61, pp. 2163-78.

40. K. Ma, H. Wen, T. Hu, T.D. Topping, D. Isheim, D.N. Seidman, E.J. Lavernia, and J.M. Schoenung: Acta Mater., 2014, vol. 62, pp. $141-55$.

41. T. Hu, K. Ma, T.D. Topping, B. Saller, A. Yousefiani, J.M. Schoenung, and E.J. Lavernia: Scripta Mater., 2014, vols. 78-79, pp. $25-28$.

42. S. Hirosawa, T. Hamaoka, Z. Horita, S. Lee, K. Matsuda, and D. Terada: Metall. Mater. Trans. A, 2013, vol. 44A, pp. 3921-33.

43. S. Lee, Z. Horita, S. Hirosawa, and K. Matsuda: Mater. Sci. Eng. $A, 2012$, vol. 546 , pp. $82-89$.

44. I.F. Mohamed, Y. Yonenaga, S. Lee, K. Edalati, and Z. Horita: Mater. Sci. Eng. A, 2015, vol. 627, pp. 111-18.

45. S. Lee, K. Tazoe, I.F. Mohamed, and Z. Horita: Mater. Sci. Eng. $A, 2015$, vol. 628 , pp. $56-61$.

46. G.E Totten and D.S. MacKenzie: Handbook of Aluminum Volume I: Physical Metallurgy and Processes, 1st ed., Marcel Dekker, Inc., New York, NY, 2003, p. 815.

47. C.A. Stickels and R.H. Bush: Metall. Trans., 1971, vol. 2, pp. 2031-42.

48. A. Yamamoto, T. Kato, and H. Tsubakino: Mater. Trans., 2004, vol. 45 , pp. 3106-13.

49. K. Oh-ishi, K. Edalati, H.S. Kim, K. Hono, and Z. Horita: Acta Mater., 2013, vol. 61, pp. 3482-89.

50. H.P. Klug and L.E. Alexander: X-ray Diffraction Procedures for Polycrystalline and Amorphous Materials, 2nd ed., Wiley Interscience, United States of America, 1974. 